\title{
Through the Lens of Teachers: The Use of Geography CAPS Textbooks, Concomitant Challenges and a Reimagining of the Textbook
}

\author{
Sadhana Manik \\ Tebogo Malahlela
}

\section{Abstract}

The latest school curriculum offering in South Africa, has been the introduction of the Curriculum and Assessment Policy Statement (CAPS) in 2011 and this has logically been followed by the production of new textbooks in 2013 aligned to the current education syllabus requirements. This paper examines the use of the Geography grade 11 and 12 CAPS textbooks and the challenges experienced by teachers (as articulated by them) in their use in two poor provinces that lie on the eastern coast of South Africa. The data emanates from a northern and southern hemisphere Geography Textbook and Pedagogy mixed methods study involving Norway, South Africa (SA), Swaziland and Zimbabwe. This paper utilizes the data generated from two instruments namely questionnaires and interviews from the South African data sets in the following two poor provinces: Eastern Cape and KwaZulu-Natal. Selected theoretical filaments deriving from Bates and Poole's (2003) SECTIONS model (a refinement from Bates, 1995, ACTIONS model) and Kasule's (2011) 'readability' of a textbook, were of significance. The findings on the CAPS textbook use reveal an immense dissatisfaction amongst the Geography teachers. They bemoaned the lack of learner access to textbooks. It was evident that textbook shortages negatively impacted on effective teaching and learning thereby affecting learner performance in the final years of schooling. Teachers also expressed their disappointment at many of the textbooks' quality with respect to inadequate and insufficient geographic content, decontextualised material, extraneous examples and some incorrect information. There were concerns that some of the current textbooks did not adequately acknowledge 
the needs of learners for whom English is a second language in these provinces. The authors recommend a reimagining of the CAPS textbooks by stakeholders to address some of the existing challenges in their use.

Keywords: South Africa, Geography textbooks, teachers

\section{Introduction}

South African school education has undergone a plethora of curriculum changes upon becoming a democracy. This has been as the result of an attempt to remove apartheid influences and to forge a curriculum best suited to the needs of the economy (local and global) and all who constitute the local population. The present curriculum amendment (called such because Government documents do not express it as a new curriculum, but rather a refinement), is called the Curriculum and Assessment Policy Statement (CAPS) (Department of Education 2011). It was introduced gradually in a stepped fashion across selected grades with the first exit examination (called matric/ grade 12) for high school learners in 2014. CAPS was gradually implemented over three years, starting with Grades R to 3 and Grade 10 in January 2012. In 2013, schools implemented CAPS in Grades 4 to 9 and Grade 11, followed by Grade 12 in 2014. Presently there is a dearth of research related to this latest curriculum addition CAPS, the textbooks that have been produced which are aligned to it and the discipline of school Geography in SA. This paper aims to partially fill that gap on the CAPS textbooks. This paper specifically aims to make an empirical contribution to high school geography textbook research in the context of SA, a country which has a transformational agenda to pursue. It examines teachers' use of the new Geography grade 11 and 12 CAPS textbooks and the challenges in its use as articulated by teachers in two poor provinces (Eastern Cape and KwaZulu-Natal) of SA.

We began this paper with a brief discussion of curriculum change postapartheid. We now proceed below to an examination of the literature, which highlights the challenges facing sub-saharan African countries concerning textbooks. Thereafter, significant theoretical influences for this paper are discussed, which emanate from the field of instructional technology/resources. We then explain the methodological design of the study, which is then followed by the findings on teachers' use of the Geography CAPS textbooks and their 
related challenges. A discussion of the main findings trails this and we conclude by arguing for a reimagining of Geography CAPS textbooks to obviate the current challenges experienced in these two poor provinces. Herein we draw on the critical insights distilled from sub-Saharan education textbook researcher, Verspoor (2008) and seminal Geography vulnerability researcher, Cutter (1996).

\section{A Glimpse at the Nuances of Textbook Research and School Geography}

Textbooks are an example of instructional technology. It is valuable to unpack the meaning of instructional technology and Omariba (2012: 24) uses Brown et al.'s (1973) definition of instructional technology which is an all encompassing definition: 'a combination of resources including people, materials, machines, facilities as well as purposes and processes that support effective and meaningful facilitation of learning'. There is consensus that textbooks are a category of instructional technology (Ayot 1986; Omariba, 2012). Instructional technology is sometimes called instructional/ pedagogic resources.

Textbook research as a field of study is extensive: spanning across countries and continents, and going back decades (Tsang 1933; Auerbach 1965). It thus has a rich history and much of the research published about textbooks lean on them being responsible for transmitting culture across time (Apple 2013; Bourdieu \& Passeron 1977; Morgan 2003) and for housing what is considered to be 'legitimate' knowledge in society (Apple 2013; Blaut 1998). The focus of many of the textbook studies outside of Africa across recent decades has been largely on national identity in textbooks (see Woolf 1996; Schiessler \& Nuhoglu 2005; Nava 2006).

There has been some criticism that in the African continent, there is limited literature in general on textbook research. Kasule (2011) writing in the developing world context of Swaziland, highlights the challenges of textbooks that is being currently experienced: namely that there are large class sizes with inadequate textbooks and centrally chosen textbooks. As with many other African countries, in Swaziland there are nationally composed textbook lists as textbooks have to adhere to the current national education syllabus to be approved by the local departments of education. This is similar to South Africa. Kasule (2011), reports that the textbooks in Swaziland have unfortunately been 
used for generations (due to a lack of curriculum change for quite some time) and therefore at the level of schools, they are in a poor condition from continuous use.

Despite the critique on the African continent about textbook research, substantial textbook research has indeed been undertaken in South Africa (Koross 2012). Locally, disciplines like History and Commerce have made inroads by undertaking textbook studies providing insights into a cross section of subfields like heritage, race and social justice (gender and inclusivity etc.). (see Nkwenti 2012; Pillay 2013 ; Maposa 2015 ). Much of the research in SA on textbooks have thus been confined to the subject of History and to a lesser extent to other subjects such as Commerce. The limited studies into textbook content in school subjects have also not been directed towards studies in high schools, as is reported on, in this paper. For example, Bryce (2011) writing from the SA primary school context on reading challenges particular to Science textbooks argues that textbooks are non-fiction and therefore a new genre for learners to begin to master as learners are not encouraged in their formative years to read such textbooks. She presents five consistent challenges experienced in classrooms drawing on evidence from available literature and from an empirical study analysing discourse and interactions between teachers and their learners. These challenges are as follows (Bryce 2011: 475):

- difficult technical language;

- dense presentation of concepts;

- superficial treatment of topics;

- information delivered in a dry, uninteresting manner; and

- a lack of organization and reader-friendly style.

Internationally, school Geography textbooks have been spotlighted in recent years from a critical geopolitical lens unpacking for example the dominant discourses in the textbooks (see Ide 2016) and representations of the 'other' (Mikander 2016). However, Geography textbook research has been sparse in the African continent and SA as mentioned above (Manik 2008; Beets \& Le Grange 2005; Ngubeni 2009; Wilmot \& Dube 2015). Noticeable though is some valuable contributions to this field by SA geographers Ngubeni (2009) and Naidoo (2013) who analysed aspects of knowledge in Geography textbooks. It is important to remember the assertions of Rotich (2004) writing 
about Kenya and Kasule, (2011)writing about Swaziland, that textbooks occupy a privileged position in classrooms in African countries with a colonial past. Therefore, in such countries, as is SA, textbooks are a significant tool for learning and perhaps the sole resource supporting teachers' articulations in certain schools. The value of textbooks for both teachers and learners should thus not be under-estimated as Raselimo (2014: 131) reported in a study that Geography teachers in Lesotho who lacked conceptual knowledge, were using a textbook to access content knowledge which they did not have, rather than using the textbook as a 'teaching resource.' Thus SA Geography textbooks are in dire need of being examined in studies given the array of school Geography textbooks that have been published since the early 1990's as part and parcel of the various democratic curricula changes from C 2005 onwards.

\section{Logistical Issues on School Textbooks and Learner Performance}

South African schools and textbooks have been in the limelight for all the wrong reasons in the past few years - lack of/ late delivery to poor provinces. The South African Human Rights Commission (2013) upon the mandate of parliament undertook an investigation into textbook delivery and commented that 'The implementation of the new curriculum has been beset with considerable difficulties arising from lack of delivery or late delivery of textbooks and workbooks to learners or the delivery of the incorrect learning materials'. Limpopo, a poor province, and four other SA provinces have opted for a school based procurement model where funding is transferred to a service provider to supply the books after schools make their choices. Both the Eastern Cape and KwaZulu-Natal, which are the cases for this paper, have what is termed a hybrid procurement system of sourcing their textbooks. This entails funds from the provincial department of education being given to schools, which then procure their own textbooks. Schools in both these two provinces were given the option of changing to a centralized textbook procurement system (SAHRC 2013). Interestingly Limpopo, Eastern Cape and KwaZuluNatal (KZN) 'outsource the facilitation of their procurement to what is termed a management agent' (SAHRC 2013: 24). The SAHRC report notes that in respect of the delivery of textbooks, that by December 2012,95\% of textbooks had been delivered to the Eastern Cape (EC) but no information on the 2013 
textbook delivery was available. By contrast, KZN received $100 \%$ of its textbooks by the end of 2012 and $99,46 \%$ in 2013 . Thus, textbook delivery in the EC appears to be lagging behind that of KZN. In respect of the other provinces, textbook delivery were as follows: Limpopo reported delivery of 99\% and $99,7 \%$ of textbooks in both the years. Provinces such as the Western Cape and Mpumalanga reported a 100\% delivery in 2012 and 2013.

\section{Quality in Textbooks}

The value of sufficient textbooks of good quality should not be underestimated. There is sufficient literature (interestingly, most of which emanates from primary schools again) which supports the view that textbooks have a positive impact on student learning (Verspoor 2008:236) thus quality school textbooks are a necessity for learners. Verspoor adds that he believes that 'the conclusions in his study apply perhaps even more forcefully to secondary education'. He argues that if there are inadequate textbooks then learners will not reach the threshold levels of learning. In his study on several countries in Sub Saharan Africa, he (2008: 236) acknowledges the harmful impact of high textbook costs on learner access, stating that 'high unit costs of textbooks often result in extremely low availability'. Manik (2008) similarly noted this finding a year earlier on the high costs of post-apartheid textbooks in SA impacting on learners being unable to afford to purchase. The argument that learners should have access to sufficient learning resources is also evident in Mudulia's study (2012: 535) which reported that 'Schools with adequate resources were found to perform better than those without'. An interesting caveat comes from Omwenga (2001) who is critical in his contention that there are many teachers who complain about a deficiency in instructional resources, but they are responsible for not using what is available.

\section{Theoretical Architecture}

Part of the theoretical architecture for this study draws on the SECTIONS model (Bates \& Poole 2003) which is an improvement on Bates (1995) ACTIONS model that addresses decision-making in the use of instructional technology/ pedagogic resources in the classroom. For this article, we prefer to use the concept 'instructional/pedagogic resource' (Walton \& Ruck 1975) as 
'instructional technology' does carry the connotation of some form of digital advancement (computer software) as Hooper and Reinartz (2002) purport. The resource being examined in this article is the paper version/ hardcopy grade 11 and 12 Geography textbooks which have a long history of physical use and can thus not be considered to be digital although some textbooks may be accompanied by a computer disc.

Another theoretical strand relevant for this paper comes from Omariba's study (2012) which investigated the types of instructional resources used and the challenges experienced by teachers and learners in secondary schools in Kisii County, Kenya. Omariba (2012: 15) argued that the 'use of instructional technologies' (pedagogic resources) are responsible for accomplishing 'mediated learning' that is 'simple, enjoyable and stimulating for the learners'. Omariba thus eschews three facets to the pedagogic resource: it has to be simple to read, enjoyable and stimulating for learners - in the case of the present study, these features of the textbooks have relevance. For this study, the specific pedagogic resource is the newly crafted Geography CAPS grade11 and 12 textbooks published in 2013. In the Bates (1995) model which Omariba (2012) draws upon, 'ACTIONS are an acronym for the description of a set of tasks central' not only 'to the informed selection' and also to 'the use of instructional technologies in classroom teaching' (Omariba 2012:12). The refinement of this model has value for us and our use of selected elements of the refinement are explained below. Although the SECTIONS model and its predecessor were initially crafted for distance education, it has been utilized in face-to-face teaching environments and 'has been found to be adaptable to various formal and informal teaching environments' (Bates \& Poole 2003: 78).

In the original model,

A therefore stands for accessibility of the textbook;

C is for cost of the textbook;

$\mathbf{T}$ is for Teaching and Learning - what instructional methods are needed in using the textbook;

I is for Interaction and User friendliness - the nature of the interaction between teachers, learners and the textbook;

the $\mathbf{O}$ is for organization - the types of organization required for facilitating the use of the technology-textbook/s; what are the barriers to using the textbook successfully? 
the ' $\mathbf{N}$ ' has been omitted for use because $\mathrm{N}$ stands for novelty - how new is the technology and what are its features and textbooks are not a new resource although the CAPS textbooks are recently produced; and

the $\mathbf{S}$ stands for speed, the swiftness with which teaching can unfold using the resource of the textbook.

In the SECTIONS model, a refinement of the ACTIONS model, 'ease of use' and 'interaction' are separated as criteria as Bates and Poole (2003) believed that if the resource is difficult to use it will impact on learning thus warranting it to be a separate criterion from interaction.

In this improved model,

the $\mathbf{S}$ is for students - what is known about the learners and how appropriate is the textbook for them;

$\mathbf{E}$ is for ease of use - how easy is the textbook for use;

$\mathbf{C}$ is for cost - the cost of the textbook for each learner;

$\mathbf{T}$ is for teaching and learning - 'the kinds of learning that is needed' and the pedagogical approaches required for this learning;

I is for the kinds of interaction this resource allows for;

$\mathbf{O}$ is for the kinds of organisation this resource requires and the barriers to be eliminated to maximize the use of the textbook;

$\mathbf{N}$ is for novelty - how new is the textbook; and

$\mathbf{S}$ is for speed - how quickly can this textbook facilitate the course/ subject.

It is thus evident that access now is collapsed within the category of students (which we will call leaners as this paper relates to school and not higher education in the SA context) and the other change is just the separation of ease of access as a separate criterion. Interestingly, the first and second models were fashioned for teaching in a digital age and therefore we as the authors contend that there are aspects of the models which are not suitable for this present study on hardcopy textbooks. We thus trim away that which is deemed irrelevant to hardcopy textbooks and alter others for our use in this paper.

Because the majority of learners in SA are African and English, the medium of instruction in KZN and EC high schools is a second or third 
language for them, the aspect of 'readability' of the textbook, is salient. Thus theoretical insights into readability is significant and aspects of readability can be linked to the ' $S$ ' in the ACTIONS model. We thus glean from the work of Kasule (2011) for this. Kasule (2011: 63) researched textbook readability in Swaziland, South Africa's neighbour. He emphasized the concept of the 'readability' of a textbook and explained that readability is 'simply as the ease or difficulty with which the textbook may be understood' (Kasule 2011: 63). Kasule further states that there is, 'a heavy responsibility on the quality of the textbook itself in meeting appropriate criteria regarding the learner's age, educational and cultural background, and linguistic proficiency'. He explains that linguistic proficiency can refer to the language contained in the textbook which learners have not yet achieved mastery of or it can refer to the discipline specific (technical concepts pertaining to each topic)language or to both of these ideas. Kasule (2011: 66) explains that 'working with academic texts that are written in a language in which one is not competent, as is the case in ESL classrooms, is not easy'. This idea has a link to Omariba's (2012) assertion of the textbook needing to be 'simple'.

\section{Methodology}

This paper derives from an ongoing north-south Geography Textbook study which commenced in 2016. The study was located within the interpretivist paradigm as the aim of the study was to explore teachers' experiences in terms of their use of the Geography CAPS textbooks published in 2013 and their related experiences and challenges. The participants were teachers from public schools who were teaching Geography in grades 11 and 12 . The data presented and discussed in this paper is extracted solely from teachers located in two provinces in South Africa that have a hybrid system of textbook procurement, as stated above. Thus one of the limitations of this study is that the provinces of SA with a school based procurement method are not included. A collective Case study approach was used for the umbrella study, with the idea that 'greater insight into a research topic' can be gained 'by studying multiple cases' (Johnson \& Christensen 2014: 436). Yin (1994) also refers to this as multiple case design. The cases are generally studied in an instrumental fashion rather that an intrinsic way (Johnson \& Christensen 2014). They also contend that this approach allows for comparative studies and the ability to generalize 
from the results possible. The aim of the larger study from which the data was extracted for use in this paper, was to explore the choice of Geography textbooks in terms of what Geography textbooks were being selected at schools, how the textbooks were being chosen (which were favoured textbooks) and why were particular textbooks selected. In addition, teachers' use of the textbooks were explored including the challenges being experienced in terms of the current offering of Geography CAPS textbooks in high school. The larger study used a mixed methods approach and two instruments were used for data generation in each country context: namely questionnaires and interviews. The trustworthiness of the data was enhanced by having multiple methods of data generation (Creswell \& Poth 2018). In total, for the large SA data set, data was generated from Geography teachers located in five poor provinces: Limpopo, Mpumalanga, Northern Cape, Eastern Cape and KwaZulu-Natal. An area for future research would be to include SA's other provinces. Purposive sampling of the cases were used because it 'illustrates some feature or process in which we are interested' (Creswell \& Poth 2018:148). Hence, the two largest data sets, with provinces using the same method of textbook procurement, were selected for discussion in this paper.

Geography teachers were located for participation by the existing Geography Education networks in higher education institutions in each of the provinces. Thus, Geography education lecturers used their links with Geography teachers and also their postgraduate students who could link them to Geography teachers as the initial sample. That is convenience sampling was first used. In addition, snowball sampling was thereafter used to draw in a larger data set using initial participants to suggest one or more of their geography colleagues who were teaching in the same grades.

The relevant ethical procedures were followed. All participants completed a consent form and were at liberty to withdraw from the study at any time should they choose to do so. All participants were also given pseudonyms to protect their identity. Reliability and Validity are important issues in all research (Lacey \& Luff 2001) and trustworthiness of the data was ensured through the following ways: the gathering of thick, rich data via open ended questions in the questionnaire and follow up questions in the interview and member checking of transcripts.

Out of an initial 60 questionnaires which were handed out, a total of 45 questionnaires were returned ( $n=26$ for KwaZulu-Natal and $n=19$ for the Eastern Cape) equating to a response rate of $75 \%$. These questionnaires 
contained numerous open-ended questions which were qualitatively analysed. A total of 6 interviews were held face to face with participants in KZN and none in the EC due to logistical and financial reasons (such as the costs to travel to remote locations to interview one teacher face to face). Teachers who completed the questionnaires had to indicate on their consent form if they would consent to a follow up interview to probe their qualitative responses in depth and if agreeable, provide their contact details.

The first part of the questionnaire gathered data on the biographical and professional profiles of teachers in the schools, how the geography textbook/s were being selected for purchase, and what were the favoured textbooks by the teachers. The open ended questions allowed for data to also be generated on how the textbooks were being used (in preparation, homework, classwork, assessment, during which part/phase of the lesson (introduction, middle, conclusion), teachers' views on the CAPS textbooks and the challenges they were facing in the use of these textbooks. In attempting to resolve their challenges by re-imagining textbook use, the approach we used was heuristic. The interview schedule additionally attempted to gather indepth data on teachers' favoured textbooks and their use of the textbooks and its related challenges. It also probed teachers' views on the nature of the CAPS Geography textbooks they were using to access textbook quality. The questionnaire and the interview schedule both included a question on teachers' additional comments related to the geography textbooks, in the event that the study may have overlooked any interesting aspects in need of probing in respect of the use and challenges in teachers' use of the CAPS Geography grade 11 and 12 textbooks.

\section{Findings}

The findings discussed below illuminated teachers' use of the grade 11 and 12 Geography CAPS textbooks prior to, during and after lessons and the concomitant challenges they experienced in using these textbooks.

\section{Teachers' Use: The Textbook at the Epicenter of Lessons}

It was evident from the questionnaires and interviews that Geography teachers in the two poor provinces of SA were using the textbooks extensively for a range of purposes from pre-lesson to post lesson: in preparation of their 
lessons, for classroom teaching, for their assessments, and for homework. It was evident that the CAPS textbooks were a salient part of Geography teachers' pedagogy. Q25 $\mathrm{KZN}^{1}$ stated, 'the textbook is used throughout the lesson'. Q13 KZN explained that there is a dependency by all teachers at her school including herself on textbooks, 'There is a heavy reliance on the textbook in my school. It is the main resource in the classroom ...'. During classroom teaching, in what is commonly termed the normative 3 part lesson, the selected textbook was used in all parts: introduction, development and conclusion of the lessons. Teachers articulated the view that the textbook served a central position in the classroom and it appeared from teachers' articulations that there was a dependency on the textbook: 'learners have to refer to somewhere and textbooks serve that purpose' (Q $14 \mathrm{KZN})$.

The development of the lesson was the favoured space for textbook use. Geography teachers asserted that the development is largely where textbooks are used as 'it helps to deliver the content easily' (Q $21 \mathrm{KZN})$ and it allows for consolidation of information from different textbooks: 'during the middle (of the lesson) is where you can combine different information from different textbooks' (Q6 EC $\left.{ }^{2}\right)$. This is especially pertinent as visual information (diagrams and pictures) and case studies are a necessity in teaching within the discipline of Geography.

It was found that the majority of teachers in the sample, felt the need to refer to multiple textbooks for different purposes. Teachers were referencing textbooks in preparation for their lessons (CAPS textbooks and at times textbooks produced pre democracy). However, in class they would only use the one CAPS textbook which learners could access and that they had decided upon within a specific cluster of schools for standardization as the grade assessments are prepared by teachers from various schools within the cluster. This is articulated by Q16 KZN who explained, 'I use the same books mentioned above because we also have papers that are common as a cluster, therefore it is important to share the same information as well'.

Due to Geography comprising of numerous sub-disciplines, teachers were also inclined to access different textbooks for different sub disciplines within Geography. They would find one textbook with a better approach to the

${ }^{1}$ Q25 KZN is questionnaire number 25 with the participant from KwaZuluNatal.

${ }^{2}$ Q6 EC is questionnaire number 6 with the participant from the Eastern Cape 
content or addressing a sub discipline with more content knowledge. For example, a teacher explained: 'Via Africa and Study and Master make it easy for learners to understand the content. Excel is good for mapwork' (Q 16 KZN). They would then use that particular textbook for information but this textbook may not have been purchased by the school for use by learners. For example, in the sub discipline of mapwork which has been proving to be challenging for Geography teachers and learners across SA (as is evident in the matric results), the teachers would inform learners about these additional textbooks but the onus would be on learners to purchase them independently of the school for their own use.

With regards to the CAPS textbooks, Geography teachers asserted that they referenced numerous CAPS textbooks for different purposes especially due to a lack of content. For example Q7 EC explained: 'We need to refer to different textbooks as one textbook may provide less information'. Similarly, Q8 KZN, stated, 'I use a variety of textbooks to draw more content and gather more resources, tasks and activities'.

\section{Textbook Use during Lessons Access to Multiple CAPS Textbooks}

Despite teachers alluding to the use of multiple textbooks, they are inadvertently denied access to multiple textbooks by their schools as only one textbook per subject is purchased for use. Teachers advanced the following comments in their questionnaires: Q13 EC ' No, I don't have access to all of them'; Q16 EC 'It's the only resource that I have in my school, I don't have access to other resources', Q18 EC, 'I chose to use the one that I'm using because it is the only resource that I have'. It must be noted that where teachers do have additional textbooks at school, it is because a publisher has left a free sample copy at the school for the teachers to order the textbook after perusal, which is then held onto by the teacher for his/her own use.

Some teachers did explain how they managed with having no textbooks purchased across the years except for the sample copy of the CAPS textbooks. They photocopy and make duplicate copies for learners from the chosen textbook. For example, Q21 KZN stated '... there is only 1 copy for me to use, it requires me to make handout photocopies all the time'. This reproduction of the textbook is illegal and the teacher did acknowledge 
knowing this but he felt that it was his way of managing a lack of Geography textbooks for his grade 12 class in a poverty stricken school.

Despite the centrality of the textbooks to teacher pedagogy, teachers complained extensively about the challenge of a shortage of CAPS textbooks for their learners and the ripple effect of this shortage on the nature of their pedagogy and the timeous completion of the grade 11 and 12 curriculum. This is detailed in the discussion below.

\section{An Old Story - Of a Shortage of Geography Textbooks for Learners}

Teachers' most prominent challenge with the CAPS Geography textbooks in terms of its use was that of learner access to the CAPS textbooks. They complained of not having adequate textbooks for their classes to use during lessons and for homework purposes. It was evident from both instruments (questionnaires and interviews) that the shortage of textbooks for learners was because of how purchases were made by the schools in both provinces. Comments point to textbook shortage as a common ongoing challenge thwarting teachers' attempts of achieving effective textbook use to maximize learning. Some of these comments are detailed below:

'Number of textbooks available. Not every learner has a textbook' (Q11 KZN).

'... not all learners have access to textbooks' (Q16 KZN).

'There is a shortage of textbooks to be used by learners ...' (Q20 $\mathrm{KZN}$ ).

'insufficient textbooks for learners' (Q22 KZN).

'shortage for instance the total number of my learners is 100 and I have only 12 textbooks of which they cannot take home' (Q7 KZN).

I 2 says, 'it will be great for every student to have their own copy'.

Q 14 EC 'Other schools have limited numbers (of textbooks) to give to me'.

The above comments chronicle a dire shortage of Geography CAPS textbooks in these two poor provinces with many Geography teachers reporting that each learner does not have access to his/her own textbook. It is extremely pertinent 
to note that Q7 KZN revealed that there is one Geography textbook per 10 learners to share in the school.

\section{Challenge: Cost of Textbooks}

The shortage of Geography textbooks is linked to the cost of the CAPS textbooks and the status of the subject. The schools in both sampled provinces were poor (inadequate funds provided by the department of education to purchase additional textbooks) and thus unable to purchase sufficient textbooks for all learners due to financial restrictions, as is explained by the teachers below.

'Shortages ... financial constraints' (Q9 KZN).

'The cost of textbooks is very high. School cannot buy for all learners' (Q23 KZN).

Teacher I $5 \mathrm{KZN}^{3}$ explained that some textbooks are in the region of R160 per book and the favoured textbook 'is about R200'.

I 3 KZN similarly stated that a challenge was the 'unit cost of textbooks which limits me in terms of my needs'. He has a total of 294 students doing Geography and says, 'its financial, the textbook problem'.

Thus textbook decisions in the schools are taken strategically based on limited textbook purchases for Geography. Teachers also noted that Geography is not considered a priority subject like English/ Afrikaans or STEM subjects and hence a full set of textbooks is never purchased as regularly as with for example English/ Afrikaans due to those subjects' needs.

The link between textbook shortage and the poverty of schools was succintly summed up by I $5 \mathrm{KZN}$ as 'We are restricted by the LTSM budget'. The LTSM (Learning and Teaching support materials) budget is the government allocated funding instrument that is awarded to schools and used to purchase textbooks. However, school classification according to the quintile system (a sliding scale from 1 - 5) which attempts to provide variable funds (LTSM budget) based on whether a school is deemed to be poor (quintile 1) or more advantaged (from quintile 2 to the most advantaged being quintile 5) appears to be flawed in addressing school poverty.

${ }^{3}$ Interview 5 for a KZN participant. 
I 4 KZN explained 'we are a quintile 1 school (disadvantaged school, that is poor) but with a quintile 5 (advantaged school) ranking. We are rated the same as Queensburgh Girls...we have learners from township and underdeveloped areas...students buy separately from their own pocket and some share cos they can't afford to buy'.

The above comments by the Geography teachers (I 4 and I 5 in KZN) draws attention to how government funding is allocated to schools and how the present quintile system of funding for schools negatively impacts on the provision of adequate Geography textbooks for all learners. Quintile 1 schools thus receive more money (which can be used to purchase more textbooks) than quintile 5 schools. The quintile system, as explained by I $4 \mathrm{KZN}$, fails to recognize that there are learners from socio-economically disadvantaged locations attending schools in areas which are socio-economically advantaged and these learners are unable to access a textbook purchased by the school because the ranking of the school translates to a lower LTSM budget which is used to purchase textbooks.

Teachers explained: 'The cost of textbooks is high...there is sharing of textbooks' (KZN Q 24).

Participant Q 13 KZN explained, the challenges of multiple variables linked to the provision of textbooks negatively impacting on teaching and learning amongst the grade 12s: large Geography class sizes, inadequate textbooks and the sharing of textbooks between Geography teachers and learners across the grade 12s. He explained, 'Due to the large number of students, all learners do not have access to a textbook, there is sharing and we share within our classes and with the other Geography educator and myself'.

His articulations reveal the logistical challenges of having to cope with a shortage of textbooks and large class sizes. It is evident that the ratio of textbooks to leaners is not 1:1, there are instances described above where it is more than 1: 10 (one textbook to more than 10 learners).

\section{Repercussions of Inadequate Geography CAPS textbooks}

There are also numerous teaching, learning and curricula repercussions as well which result from an inadequate number of Geography textbooks for learners per class. These include teachers reporting that there is a wastage of teaching 
and learning time in class and that they experience difficulty in completing the grade 12 curriculum timeously.

' shortage of textbooks ... so I have to write notes for learners (on the board) and this consumes time' (Q $20 \mathrm{KZN})$.

'... the department is coming down heavily on poor results' (I $2 \mathrm{KZN})$. Teachers did suggest that, '... it would be better if learners have their own textbook that they can go home with it' (Q $21 \mathrm{KZN})$.

I $5 \mathrm{KZN}$ explained, 'most of the time, I write on the board. I use the study guide and my own notes. I don't give learners books to take home .... there's no paper and no ink so I can't turn out. They only gave 12 copies (of the textbook). I was at another school for 12 years and they have all the resources and I used to produce 25 as out of a class of 26. Because there's not enough resources, learners do battle and it does impact on the results'.

It is clearly evident from I $5 \mathrm{KZN}$ that he has experienced teaching Geography in a well resourced school for numerous years and produced excellent matric results and comparatively he is able to see that a shortage of Geography textbooks is impacting on the learners' performance in the present poor school where he is teaching.

It is also important to note that the Geography teachers explained that they are unable to utilize the textbooks from the previous curriculum offerings due to the requirements for CAPS assessments and because of content changes in the new curriculum. For example, I $2 \mathrm{KZN}$ stated 'some of the grade 12 content has been moved to the grade 11 syllabus' and also in the 'previous curriculum, there was a focus on activities and not content' (I 3 KZN).

\section{Quality of CAPS Textbooks}

We now turn to the quality of the CAPS Geography textbooks. It was evident that, there were few Geography CAPS textbooks which were considered to be of high quality enhancing teaching and learning in the classroom as expressed by Q $12 \mathrm{KZN}$ of one textbook, 'Excellent resource to use in the classroom with learners' and Q $17 \mathrm{KZN}$ of 2 other textbooks which were deemed, 'rich in content'. Other textbooks were merely perceived by teachers to have adequate 
content and some were lacking in numerous ways. For example, Q $10 \mathrm{KZN}$ stated the 2 textbooks which she used were 'simple for learners, illustrations can be copied and used in class'. ; Q $11 \mathrm{KZN}$ stated, 'well illustrated simple diagrams'; Q3 EC stated that the textbook used was, 'easy for learners to follow'.

Despite the above articulations by teachers that they were selecting and using textbooks based on aspects of the 'readability' of the textbook, there were overwhelming challenges expressed by the majority of Geography teachers which centred on various quality aspects of the content in many of the textbooks as stated above. Interestingly, the textbooks, which were perceived by teachers to be lacking had passed the Department of Basic Education's quality screening process and made the recommended textbook list. Q14 EC commented on the content of one such textbook, '... with almost satisfying information'. These challenges related to textbook quality as reported by the participants, are discussed in depth below. Given the many challenges facing Geography teachers using the textbooks, there was a common view that some of the CAPS Geography textbooks were limited quality wise in multiple ways. The aspects of poor quality that the participant teachers alluded to included aspects related to the written content and the visuals contained in the textbooks.

\section{Written Content}

Q13 EC stated, 'some other textbooks are lacking the information or it's not shooting straight to the point, meaning its full of irrelevant information'.

Q 12 EC, 'some information is distorted'.

Q 7 and $10 \mathrm{EC}$ amongst others both commented on the textbooks having 'wrong diagrams' and 'a lack of information'.

Q 11 KZN stated , 'Certain concepts need greater explanation'.

Q $21 \mathrm{KZN}$, 'if the textbook does not cover all content information, I will have to substitute with another'.

It is apparent from the above that numerous teachers complained of inadequate, distorted and irrelevant geographic content. This was another challenge facing teachers in their use of the selected textbook: 
The argument of incorrect and confusing information was bolstered by other participants' similar comments. For example: a participant (Q 14 KZN) explained that textbooks referred to concepts differently: topographic rain' and another textbook called it 'orographic rain' ... they contain errors' ... 'some have false information'.

Also, when only one textbook is used for teacher's understanding, that is if the teacher is overly reliant on extracting the content knowledge only from this singular textbook without undertaking research via other textbooks, this has pitfalls. A participant from KZN explained, 'there is some superficial teaching and reliance on 1 textbook ... we picked this up at the marking centre ... students in the hydrology section were giving the shape (dendritic) instead of the underlying rock structure' (I 1, KZN).

\section{Textbook Visuals}

Teachers also experienced challenges related to the nature of the visuals in the textbooks as is detailed below:

Q10 EC stated that there were 'wrong diagrams, lack of information'. Similarly, Q16 EC noted that, 'The textbook doesn't show illustrations, give examples and a memorandum for assessment'.

Where there were visuals in many textbooks, some teachers did comment on the poor resolution of the pictures and a mismatch between the diagrams and the corresponding content. For example, Q8 EC noted 'sometimes the information is wrong and diagrams do not match with the content'.

\section{A Lack of Alignment between Local Context and Textbook Examples}

Additionally, some of the textbooks contained examples/illustrations that were irrelevant to life in South Africa, which teachers felt compromised learners' understanding of geographic concepts and phenomena that could impact on building a better understanding of their locality. For example, 
Q10 EC noted that there were 'no local illustrations or examples from our local areas'. Similarly, Q14 EC stated, 'They always show very far areas'. Q17 KZN similarly stated that 'some textbooks make or give examples that are outside of your region and country'.

The absence of contextualised examples were thus another challenge emanating from the CAPS textbooks that hindered learners' conceptual understanding.

\section{User-Friendliness of Textbooks}

A major challenge for teachers was the user friendliness of the textbook. Whilst there were many teachers who referred to some textbooks as being simple and easy to follow/ understand (see Q7 KZN), there were some textbooks that were found to be unsuitable for learners for whom English is a first additional language at school. For example, Q2 KZN stated, 'inappropriate language'. Q19 KZN also explained 'we have a problem with literacy and numeracy skills ... the textbook is about language, they are reading'.

Teachers also articulated the need for each textbook to have a detailed glossary of concepts which learners could utilize as the learners are mostly English second language learners. For example,

Q12 EC commented : 'The glossary is important to get definition of concepts'.

Q10 EC stated : 'Use of index can help to define most of geographical concepts'.

Q9 EC also noted: 'Glossary helps with concepts which needs to be defined by the learners'.

It was thus evident that the teachers required textbooks to contain two aspects to enhance the readability of the textbook amongst ESL learners: a detailed glossary and an index, which would assist learners to understand new Geographic concepts.

\section{Discussion}

Whilst the CAPS curriculum revision appears to have positive overtones (Wil- 
mot \& Dube 2015), this paper has presented data in two poor provinces of South Africa which highlight, from teachers' perspectives, that the Geography textbooks which are aligned to this curriculum for grade 11 and 12 Geography, does present numerous challenges. The participant teachers utilized textbooks extensively in all segments of their lessons and they can be thus be perceived pedagogically to be textbook teachers due to their strong dependency on the textbook. This is not unusual as Kasule (2011) also writing on the role of textbooks in Southern Africa, contends that they occupy a position of privilege in the classroom because textbooks are still the most commonly available instructional resource for schools (Omariba 2012). As far back as 1999, Van Harmelen, reported that in apartheid SA, a textbook approach to teaching was quite evident. It now appears that despite government's several attempts at democratising the curriculum and teachers' roles, teachers in the two provinces of KZN and EC, have not extended their pedagogical approaches. This teaching approach with a strong reliance on the Geography textbook, from introduction to conclusion of the lesson, has not altered over the years from apartheid to democracy.

Despite this textbook reliance, the restricted accessibility of the CAPS Geography textbooks for teachers and learners was a significant challenge due to the LTSM budget allocation for the schools, which was dependent on the Department of Basic Education's (DBE)'s quintile ranking of the schools. High unit costs of textbooks and differentially priced Geography textbooks influence the quantity of geography textbooks, which are eventually purchased. Geography is also not a high status subject at SA schools and other subjects higher up in the hierarchy were subject to preferential textbook orders. Thus, the languages and STEM (especially Science and Mathematics) departments received CAPS textbook purchases more frequently because management is more understanding of their requirements. There are SSA countries which are struggling with large classes, that is teacher-learner ratios are high, for example Malawi (Nampota 2011) and Swaziland (Kasule 2011) and their findings echo in the two provinces of SA in this study. Thus the findings resonate with Kasule's (2011) that classes are large and that there is a shortage of textbooks. Correspondingly, socio economic imperatives at the schools impact on learners' access to textbooks and consequently learner achievement: learners in poor provinces rely on the purchase of textbooks via the school because they are poor and unable to purchase their own textbooks. 
Geography CAPS textbook orders placed by the school management were thus never full sets to cater for each learner and hence learners and teachers were sharing textbooks. This sharing of textbooks amongst learners and the borrowing of textbooks between classes were teachers' attempts at managing the limited textbooks at a micro level regardless of the high ratio of learners to a textbook. The agency of some Geography teachers was thus evident in their coping mechanisms linked to the high unit cost of textbooks and inadequate textbooks in class.

Omariba (2012) reported in a textbook study that completing the syllabus on time for adequate preparation of the exit examination is essential. Hence, the loss of time suffered by Geography teachers in KZN and EC due to a shortage of textbooks has negative repercussions for learners' performance in the high stakes matric exit examinations. Other scholars also commented upon this. For example, Bryce (2011: 474) found that 'most of the low performing schools were located in the low socio-economic neighbourhoods'. Masitsa (2004) found that there were four critical determinants of underachievement among township secondary school learners in SA: and one of these was the shortage of textbooks. Mudulia (2012: 531) additionally reported that 'the need for course books and revision books in the ratio of 1:1 cannot be overemphasized if learners are to do extra work on their own'. Thus studies have indicated that SSA countries have a longstanding challenge of inadequate textbooks and SA is no different and this has a negative impact on learner performance. In democratic SA, when the African National Congress came into power as the ruling party, there was political rhetoric of a 1:1 ratio of learner to textbook as a target to achieve (SAHRC 2015 b). More than 20 years into a democracy with the ANC, this has not occurred. In 2015, the SCA held that 'the law is clear .... The DBE is obliged to provide a textbook to every learner to ensure compliance with section 29(1)(a) of the Constitution. We must guard against those who are most vulnerable. In this case we are dealing with the rural poor and with children. They are deserving of Constitutional protection' (SAHRC 2015 a). The ANC is still ruling, and this court ruling of three years ago has not reached fruition. The shortage of textbooks will not abate anytime soon with growing numbers of matriculants and annual complaints of late delivery of textbooks for matric learners in poor provinces which continues to engender rage from lobby groups (SAHRC 2015 a). It is evident that the costs of textbook production remain high and so does the need for textbooks. 
Interestingly, teachers were selecting textbooks for use based on the readability of the textbook (Kasule 2011), the textbook needing to be 'simple' (Omariba 2012) and caveats such as learners' needs, ease of textbook use and the cost (Bates \& Poole 2003) of the pedagogic resource. Teachers were thus selecting textbooks for use by largely ESL learners. Catering for ESL learners because they are not proficient 'linguistically (Kasule 2011) is essential for the majority of KZN and EC learners who are African and for whom English is a second language. The teachers articulated numerous challenges they were experiencing related to the quality of the current CAPS textbooks, which is of concern as these textbooks have passed a screening process by the DBE. Teachers' critique of textbooks should be viewed in a positive vein as these local teachers are in a position to comment and challenge the content given their Geography knowledge base. Recently, Biddulph, Lambert and Balderstone (2015) also noted that Geography teachers in the UK appeared to be quite critical of their textbooks. The quality of the local CAPS textbooks related to numerous issues, most especially that CAPS textbooks were content deprived.

It was evident that the teachers sampled were utilizing multiple Geography textbooks as reference material in preparation and during their lessons. They did report on limited content knowledge (in building conceptual understanding for themselves and learners) in some of the CAPS textbooks (those textbooks that they could access via the school LTSM budget). Interestingly, the CAPS curriculum was reported as a return to a content based curriculum (Wilmot \& Dube 2015) and yet the textbooks still appeared to be content deprived according to the participating grade 11 and 12 Geography teachers. The CAPS textbooks have been approved at national level and Blaut (1998: 46) notes that the textbook due to its screening process by the department of education is 'a vetted social statement of what is considered valid and acceptable for entry into the mind of the child'.

Participant teachers expressed disappointment that some of the screened textbooks contained incorrect, limited and decontextualized geographical information and were thus lacking in appropriate quality for their grade 11 and 12 learners. Another previous study on textbooks in Africa also drew attention to how textbook authors were glossing over topics (lacking in depth), fell short of easy navigation by the readers, and contained disciplinary language that was dense. Drawing on Raselimo's (2014) concepts of 'interdiscursive relations' and 'decontextualisation', it is evident that the teachers in the present study did expect the CAPS Geography textbooks to integrate 
geographical vocabulary and content with local knowledge and link topics with local issues in the country in the form of examples/ case studies.

Incidentally, the quality of Geography textbooks is not only a concern in this particular study, and as recently as 2014 and 2015, it was of concern in England and the Publisher's guide of 2015 sought to provide guidelines on how to ensure the requisite quality in Geography textbooks. Lee and Catling (2016:12) reported that Geography textbooks should contain: ' the author's voice which should appear clearly in the subject context, the focus on geography content, and its selection including the use of 'real life case studies', the provision of challenging tasks which involve reading and interpreting text, graphs and maps, and thoughtful design of the book and its layout. Such a resource should support teachers and be accessible and easy to follow for pupils'. Evidently, this is not the case with some of the CAPS textbooks given the local teachers' critique.

\section{Recommendations and Conclusions}

A significant aspect of the findings, revolved around SA teachers' experiences of the shortage of the CAPS grade 11 and 12 Geography textbooks. This signaled a plethora of challenges on access and use of CAPS textbooks that largely hinged on school poverty by virtue of the teachers being located in the poorest of provinces of SA with low human development indices (which measures life span, knowledge and standard of living). Statistics South Africa's (SSA) report (2017:14) on poverty trends between 2006-2015 revealed that inspite of a drop in poverty between 2006 and 2011, poverty began rising in 2015 and 'the country has lost ground in the war on poverty'. SSA (2017:18) revealed that 'in general Black African females, children (17 years and younger, people from rural areas, those living in the Eastern Cape and Limpopo and ... are the main victims in the ongoing struggle against poverty'. Thus schools trapped in poverty denote a cycle of disadvantage that threatens to not only entrench but exacerbate the historical suffering of learners from poor contexts such as those who are located in KwaZulu-Natal and the Eastern Cape provinces of SA. The sharing of textbooks by learners is clearly a stop-gap measure implemented by teachers that is not sustainable and it negatively impacts on achieving quality teaching and learning. Clearly textbook shortages hinder learners' performance outcomes in these poor provinces. 
In the nineties, acclaimed risks and hazards Geographer, Susan Cutter (1996) conceptualized a model of vulnerability based on place, called the hazards of place model. Indeed KwaZulu Natal and the Eastern Cape are also conceptualized as vulnerable provinces due to poverty. But, there is a need to move away from the normative lens of the vulnerability of these provinces to how they can be propelled to germinate resilience as Cutter's later work demonstrated. Locally, this will be in attempts to creatively address a lack of Geography CAPS textbooks in the classroom which is undoubtedly compromising quality teaching and learning.

Resilience related to the use of Geography CAPS textbooks can be developed through a multi-pronged, multi-level re-imagining of the textbook in an attempt to obviate some of the challenges. As was evident, some teachers were already demonstrating resilience in numerous ways. They shared textbooks amongst learners and between themselves. They were critical of the textbooks and they were sourcing multiple textbooks for content, being well aware of the poor quality of content in some of the textbooks and resorting to using others to supplement the content knowledge for learners. The Geography teachers identified the user-unfriendliness of certain textbooks given their ESL learners and they acknowledged that they were using multiple textbooks in their own preparation of lessons in an attempt to boost lesson quality. However, other ways of developing resilience can be promoted:

Macro level: The SA government does not regulate the costs of the textbooks on their approved list, this is a change at the macro level which is needed: for government intervention together with publishers. The buck does not stop with textbook approval via a screening of the textbooks by government, because the bottleneck is in the price of the Geography textbooks, a point I raised 10 years ago in another textbook study (Manik 2008). Government and publishers need to reimagine their respective roles in the provision of adequate textbooks for access by learners if learner performance in the poorest provinces in SA is to be addressed with the seriousness it rightfully deserves. Additionally, textbook publishers do need to revise their textbooks to incorporate contextualized, correct information with a level depth for the required grade of learners.

Meso level: Schools do need to reimagine their role in the provision of access to textbooks for their Geography learners by exercising their agency and 
maximizing the use of their libraries. This was also a key suggestion by Verspoor (2008) on the underutilization of libraries and ways on how libraries could assist to address the textbook shortage. Schools need to purchase multiple copies of subject textbooks for their libraries to place on reserve for learners to use when ever they have time: during school hours, mornings and afternoons. Teachers also need to motivate school management to assist with innovative ways to meet their discipline requirements. Therefore, if there is inadequate funding to buy an entire set of CAPS textbooks, schools should rather buy a few copies for the library instead of having to wait a few years until there is adequate funding for an entire set of Geography books. The corporate sector can also be a source of textbook sponsorship for schools.

Micro level: There are teachers who did reimagine their role in accessing textbooks for use in their classes through sharing of textbooks, but the school did not timetable Geography in the grades in such a way to prevent subject clashes. Thus, creative timetabling of the Geography periods for the same grade could alleviate this experienced challenge. This was also a suggestion by Verspoor (2008) in his study of textbooks in SSA. It is evident that teachers need to exercise their agency and work with school management and industry on finding sustainable solutions for textbook challenges at grassroots level.

Hence, a re-imagining of geography CAPS textbooks is direly needed: A lens that's not tinted towards an ongoing cry for one textbook per learner. This lens should endeavor to address as many of the current challenges of the CAPS Geography textbooks and teachers' use of the textbooks through resourceful strategies as some Geography teachers have been demonstrating resilience in their attempts to compensate for the lag in quantity and a lack of quality of the current Geography CAPS textbooks for grades $11-12$. This of course does not exonerate either publishers of the textbooks and government who will need to re-examine the grade 12 textbooks for the quality concerns raised above, given the challenges that the teachers reported.

\section{References}

Apple, M. 1988. Teachers and Texts. London: Routledge

Apple, M. 2013. Knowledge, Power and Education: The Selected Works of Michael W. Apple. New York: Routledge. 
Through the Lens of Teachers: The Use of Geography CAPS Textbooks

Auerbach, F.E. 1965. The Power of Prejudice in South African Education: An Enquiry into History Textbooks and Syllabuses in the Transvaal High Schools of South Africa. Cape Town: Balkema.

Ayot, H.O. 1986. Instructional Materials for Educational Communication and Technology. $1^{\text {st }}$ Edition. Nairobi: Kenyatta University, Kenya Bates, A.W. 1995. Teaching, Open Learning and Distance Education. Routledge: New York.

Bates, A.W. \& G. Poole 2003. A Framework for Selecting and Using Technology. In Effective Teaching with Technology in Higher Education:

Foundations/ or Success. San Francisco: John Wiley \& Sons.

Ballantyne, R. 1999. An Analysis of Geography Teacher Educators' Perceptions of Curriculum 2005. South African Geographical Journal 81, 2: $75-79$.

https://doi.org/10.1080/03736245.1999.9713665

Beets, P. \& L. le Grange. 2005. Geography Education in South Africa after a Decade of Democracy. Geography 93: 267 - 277.

Biddulph, M., D. Lambert \& D. Balderstone 2015. Learning to Teach Geography in the Secondary School: A Companion to School Experience. $3^{\text {rd }}$ Edition. Abingdon: Routledge.

https://doi.org/10.4324/9781315771274

Blaut, J. 1998. The Colonizer's Model of the World. New York: Guilford Press. Bourdieu, R. \& J. Passeron 1977. Reproduction in Education, Society and Culture. London: Sage.

Bryce, N. 2011. Meeting the Reading Challenges of Science Textbooks in the Primary Grades. The Reading Teacher 64,7: 474 - 485.

https://doi.org/10.1598/RT.64.7.1

Chisholm, L. et al. 2000. A South African Curriculum for the Twenty-first Century: Report of the Review Committee on Curriculum 2005. Pretoria: Department of National Education.

Creswell, J.W. \& C.N. Poth 2018. Qualitative Inquiry and Research Design: Choosing among Five Approaches. $4^{\text {th }}$ Edition. Thousand Oaks California: Sage.

Cutter, S. 1996. Vulnerability to Environmental Hazards. Progress in Human Geography 20,4: 529 - 539.

https://doi.org/10.1177/030913259602000407

Dale, E. 1969. Audio-Visual Methods in Teaching. $3^{\text {rd }}$ Edition. New York: The Dryden Press. 
Department of Education 2011. Curriculum Assessment Policy Statements (CAPS). Available at:

http://www.education.gov.za/Curriculum/CurriculumAssessmentPolicyS tatements/tabid/419/Default.aspx (Accessed on 5 June 2018).

Hooper, S. \& T.J. Reinartz 2002. Educational Multimedia. In Reiser, R.A. \&

J.V. Demps (ed.): Trends and Issues in Instructional Design and

Technology. New York: Pearson Education Inc.

Jansen, J. \& P. Christie (eds.) 1999. Changing Curriculum: Studies on

Outcomes-based Education in South Africa. Kenwyn: Juta and Co Ltd. Johnson, K. 2000. Readability and Reading Ages of School Science Textbooks.

Available at: http://www.timetabler.com/reading.html. (Accessed on 6 July 2018).

Johnson, R.B. \& L.B. Christensen 2014. Educational Research: Quantitative, Qualitative, and Mixed Approaches. $4^{\text {th }}$ Edition. California: Sage.

Kasule, D. 2011. Textbook Readability and ESL Learners. Reading and Writing 2,1: 63 - 76. https://doi.org/10.4102/rw.v2i1.13

Koross, R. 2012. National Identity and Unity in Kiswahili Textbooks for

Secondary School Students in Kenya: A Content Analysis. Journal of Emerging Trends in Educational Research and Policy Studies (JETERAPS) 3, 4: 544 - 550.

Lacey, A. \& D. Luff 2001. Research and Development in Primary Healthcare: An Introduction to Qualitative Analysis. London: Trent Focus.

Lee, J. \& S. Catling 2016. What do Geography Textbook Authors in England Consider When They Design Content and Select Case Studies? International Research in Geographical and Environmental Education 1 - 16. Manik, S. 2008. (En)viable Attempts at Addressing Education for Sustainable Development through New Geography Textbooks in Post-Apartheid South Africa. International Textbook Research 30, 2: 621 - 638.

Maposa, M.T. 2015. Reflections on Applying Critical Discourse Analysis Methodologies in Analysing South African History Textbooks. Yesterday \& Today 14: 58 - 75.

https://doi.org/10.17159/2223-0386/2015/n14a3

Marchesi, N. 2017. SAHRC Agrees to Investigate Textbook Delivery Failures.

6 March online News broadcast. Available at:

https://www.da.org.za/2017/03/sahrc-agrees-investigate-textbook-

delivery-failures/. (Accessed on 2 June 2018).

Masitsa, G. 2004. Four Critical Causes of Underachievement in Township 
Secondary Schools. Acta Academica 36, 1: 213 - 245.

Mikander, P. 2016. Westerners and Others in Finnish School Textbooks. Published PhD Thesis. University of Helsinki, Finland.

Morgan, J. 2003. Imagined Country: National Environmental Ideologies in

School Geography Textbooks. Antipode 444 - 462.

https://doi.org/10.1111/1467-8330.00334

Mudulia, A.M. 2012. The Relationship between the Availability of Teaching/

Learning Resources and Performance in Secondary School Science

Subjects in Eldoret Municipality. Kenya Journal of Emerging Trends in

Educational Research and Policy Studies (JETERAPS) 3,4: 530 - 536.

Naidoo, D. 2013. Exploring the Recontextualisation of the Discourse of

Geography in Textbooks. Journal of Education 58: 153 - 177.

Nampota, D. 2011. Exploring the Potential and Challenges of Integrating

Environmental Issues in Formal Education in Malawi. African Journal of

Research in MST Education Special Issue 15, 3:137 - 152.

Nava, C. 2006. Facets of National Identity. Lanham: Rowman and Littlefield.

Ngubeni, T.D. 2009. A Knowledge Analysis of Grade 12 Geography Textbooks

Used in South African Schools. Unpublished Masters in Education.

University of KwaZulu-Natal, Pietermaritzburg.

Nkwenti, F. 2012. Heritage in Contemporary Grade 10 South African History

Textbooks: A Case Study. Unpublished Masters in History Degree,

University of KwaZulu-Natal, Pinetown.

Omariba, A. 2012. Challenges Facing Teachers and Students in the Use of

Instructional Technologies: A Case of Selected Secondary Schools in Kisii

County, Kenya. Unpublished Masters in Education thesis, Kenyatta University, Kenya.

Pingel, F. 2010. UNESCO Guidebook on Textbook Research and Textbook Revision. ${ }^{\text {nd }}$ Revised and Updated Edition. Paris: Unesco, and the GeorgEckert Institut.

Pillay, P. 2013. Gender Representation in Contemporary Grade 10 Business

Studies Textbooks. Unpublished Masters Degree in Social Sciences, University of KwaZulu-Natal, Pinetown.

Raselimo, M. 2014. Integration of Environmental Education into Geography

Lessons: Is there Change in School Geography following the LEESP Intervention? South African Geographical Journal 96, 2: 119 - 133.

https://doi.org/10.1080/03736245.2013.847800

Rotich, C.D. 2004. The Affordability of School Textbooks in Kenya: Consu- 
mer Experiences in the Transforming to a Liberalising Economy. Nordic Journal of African Studies 13,2: 175 - 187.

SAHRC (a) 2015. Available at:

http://www.sahrc.org.za/home/indexe459.html?ipkMenuID=\&ipkArticle $\underline{\mathrm{ID}=358}$. (Accessed on 7 June 2018.)

SAHRC (b) 2015. Available at:

https://www.sahrc.org.za/home/21/files/Delivery\%20of\%20Learning\%2 0Material\%20Report\%20Final\%20.pdf (Accessed on 7 June 2018).

SAHRC 2017. Update on the South African Human Rights Commission's Intervention on Limpopo Textbooks and Stationery. Available at: https://www.sahrc.org.za/index.php/sahrc-media/news-2/item/525update-on-the-south-african-human-right-commission-s-intervention-onlimpopo-textbooks-and-stationery. (Accessed on 7 June 2018).

Schiessler, H. \& S. Nuhoglu 2005. The Nation, Europe and the World. Textbooks and Curricula in Transition. New York: Berghahan Books.

Statistics South Africa (SSA) 2017. Poverty Trends in South Africa: An Examination of Absolute Poverty between 2006 - 2015. SSA: Pretoria.

Tsang, C. 1933. Nationalism in School Education in China since the Opening of the 20th Century. Hong Kong.

Van Harmelen, U. 1999. 'Where has all the geography gone?' A Social Constructivist Perspective of Curriculum 2005. South African Geographical Journal 81, 2: 80 - 85.

https://doi.org/10.1080/03736245.1999.9713666

Verspoor,A.2008. At the Crossroads: Choices for Secondary Education in SubSaharan Africa. African Development Series. Washington: World Bank.

Walton, J. \& J. Ruck 1975. Resources and Resource Centres. London: Ward Lock Educational.

Wilmot, D. \& C. Dube 2015. School Geography in South Africa after Two Decades of Democracy: Teachers' Experiences of Curriculum Change. Geography 100, 2: 94 - 101.

Wilmot, D. 2005. The Development Phase of a Case Study of Outcomes-based Education Assessment Policy in the Human and Social Sciences Learning Area of C2005. South African Journal of Education 25, 2: 69 - 76.

Woolf, S.J. 1996. Nationalism in Europe. 1815 to the Present: A Reader. London: Routledge.

Yin, R. 1994. Case Study Research Design and Methods: Applied Social Research and Methods Series. $2^{\text {nd }}$ Edition. Thousand Oaks, CA: Sage. 
Through the Lens of Teachers: The Use of Geography CAPS Textbooks

Sadhana Manik Geography Education University of KwaZulu-Natal manik@ukzn.ac.za

Tebogo Malahlela Geography and Geography Information Systems University of Limpopo tebogo.malahlela@ul.ac.za 